\title{
Bilateral distribution of implantation sites in small mammals of 22 North American species
}

\author{
Donna Day Baird* and Elmer C. Birney \\ Bell Museum of Natural History, University of Minnesota, Minneapolis, MN 55455, U.S.A.
}

\begin{abstract}
Summary. The distribution of activity between the left and right sides of the reproductive tract, as measured by numbers of CL, embryos and placental scars, was studied in small mammals of 22 species. Shrews ovulate from the two ovaries in a distribution that does not differ from the binomial. Implantation of blastocysts in the two uterine horns is more nearly even ('balanced') than would be predicted from the binomial distribution. Balance in this group apparently is achieved by transuterine migration of blastocysts, perhaps in conjunction with some spacing mechanism within the uterus. Some cricetid rodents show little or no balance, but in others the distribution of activity sites (embryos, CL and placental scars) departs significantly from the binomial distribution. Reproductive activity sites of heteromyid and geomyid rodents (Geomyoidea) are highly balanced; uterine balance apparently is achieved by means of ovarian rather than uterine control.

We know of no previous reports of ovarian balance and suggest that physiological mechanisms controlling numbers of ovulations in the species exhibiting this characteristic may differ from those in species exhibiting a random distribution of ovulation sites. Hypotheses regarding evolutionary aspects of balance are considered in phylogenetic and ecological terms, generating several testable research questions for physiologists, anatomists, and evolutionary ecologists.
\end{abstract}

\section{Introduction}

Reproduction in mammals typically is thought of as being characterized by bilaterality, although exceptions long have been known (Asdell, 1964, 1966). For example, females of some species of bats (Wimsatt, 1979), caviomorph rodents (Pearson, 1949; Weir, 1971), and cetaceans (Slijper, 1949; Ohsumi, 1964) are known to use predominantly one side of the reproductive tract. Most polytocous mammals, however, tend to use both sides, but in some species a majority of ovulations and/or implantations may occur on one side (Asdell, 1964). Finally, it also has been noted that in polytocous mammals the distribution of reproductive sites (CL, embryos and placental scars) may be essentially random or they may be more equally distributed between the two sides of the reproductive tract at each reproductive effort than would be expected by chance. We refer to this nonrandom equalization of the left and right sides as 'balance'.

Balance of implantation sites has been reported for mammals of several groups, including: shrews, Sorex araneus (Brambell, 1935) and S. minutus (Brambell \& Hall, 1936); bats, Pipistrellus subflavus, Eptesicus fuscus (Wimsatt, 1945), and Chalinolobus gouldii (Kitchener, 1975); and hyrax, Procavia capensis (Millar, 1971). Similarly, we are not the first to find no significant departure from random left-right activity of the reproductive tract (e.g. Brambell \& Rowlands, 1936, for Clethrionomys glareolus; Danforth \& de Aberle, 1928; Falconer, Edwards, Fowler \& Roberts, 1961;

\footnotetext{
* Present address: Epidemiology Branch, Biometry and Risk Assessment Program, National Institute of Environmental Health Sciences, Research Triangle Park, NC 27709, U.S.A.
} 
McLaren, 1963, for Mus musculus). No one, to our knowledge, has attempted systematic analysis of reproductive balance in polytocous mammals. The several recent syntheses on evolution and associated adaptations of reproduction in mammals (e.g. Weir \& Rowlands, 1973; Millar, 1977, 1981) do not discuss the question of left-right reproductive activity, focussing instead on questions more relevant to theoretical concepts of life history evolution (see also Stearns, 1976, 1977). In a review of reproductive cycles in non-primate eutherians, Rowlands \& Weir (1984) note the marked asymmetry in activity of the sides of the reproductive tract of some mammals, but do not discuss balance. Although reproductive balance has not been generally discussed, intrauterine migration of blastocysts, one of the mechanisms by which uterine balance of implantation sites can be achieved, has been noted for many species (Boyd, Hamilton \& Hammond, 1944). Our data and discussion deal only with polytocous mammals because in monotocous mammals each litter is, by definition, as balanced as possible.

We examined specimens of 22 species of North American small mammals to assess the degree of balance in bilateral reproductive activity. The objectives of this paper are to present those data in relation to presumed phylogeny, and to consider whether balance of implantation sites is accomplished by regulatory mechanisms in the ovary or in the uterus. Finally, we raise questions about the evolution of balance in relation to embryo crowding, mode of locomotion, size of young, and size of litter. We hope that this report will stimulate field mammalogists to search their unpublished data and analyse additional species for balance; that reproductive anatomists will provide additional descriptions of uterine morphology; and that reproductive physiologists will search for the regulatory mechanisms of bilateral control in those species that show balance.

\section{Materials and Methods}

Our data originated from necropsy of animals trapped from natural populations. Populations studied were primarily those at grassland and desert study sites of the International Biological Programme (for specific localities, see Reichman \& van de Graaff, 1975; French, Grant, Grodzinski \& Swift, 1976). Some information was obtained from field work in Montana (Lampe, Jones, Hoffmann \& Birney, 1974) and Minnesota (Timm, 1975; Kalin, 1976; Baird \& Birney, 1982; Baird, Timm \& Nordquist, 1983). In a few instances, data for species not available to us were solicited from colleagues (see 'Acknowledgments').

Embryos were counted from unaided visual inspection of excised reproductive tracts; the few resorbing embryos we observed were not included in embryo counts in an attempt to evaluate uterine balance at term. Placental scars and corpora lutea (some early corpora albicantia may have been included) were counted with the aid of binocular dissecting microscopes. Only for the gophers, Geomys bursarius, was it necessary to section and stain ovaries to make repeatable counts of CL. Total observable scars in the uteri were recorded without differentiation by degree of pigmentation or striation. The few females with more than 10 scars were not included in analyses of scar counts because of the difficulty in identifying separate scars. Scar counts were not included for pregnant females because of the difficulties in making accurate counts of scars in distended uteri. Females having only a single embryo, CL or placental scar were not included in our assessment of balance. Each reproductive activity site (embryos, scars or CL) for each species was analysed separately. Our minimum sample size for analysis was 10 females.

To assess balance in a species, the $\chi^{2}$ test was used to compare observed distributions of embryos, scars and CL with expected values computed from the binomial distribution. For each litter size we assigned every possible left to right ratio of activity sites to either of two categories of the appropriate binomial distribution: 'balanced' or 'unbalanced' (Table 1). The two categories were defined such that each had an expected probability as near as possible to one half. Sequential litter sizes were pooled for analyses when the expected number of females in either category of a given litter size was less than 5.0. In all other instances a separate $\chi^{2}$ value was calculated for each 
Table 1. Expected probability parameters for a random distribution between the left and right sides of the reproductive tract

\begin{tabular}{|c|c|c|c|c|c|c|c|c|}
\hline \multirow{2}{*}{$\begin{array}{c}\text { No. of } \\
\text { activity sites } \\
\text { per female* }\end{array}$} & \multicolumn{2}{|c|}{$\begin{array}{l}\text { Percentage change } \\
\text { to balance } \dagger\end{array}$} & \multicolumn{3}{|c|}{ Balanced distributions $\ddagger$} & \multicolumn{3}{|c|}{ Unbalanced distributions } \\
\hline & Litters & Sites & Ratio & Probability & $\begin{array}{l}\text { No. of switches } \\
\text { to balance }\end{array}$ & Ratio & Probability & $\begin{array}{l}\text { No. of switches } \\
\text { to balance }\end{array}$ \\
\hline 2 & $50 \cdot 0$ & $25 \cdot 0$ & $1: 1$ & 0.500 & 0 & $2: 0$ & 0.500 & 1 \\
\hline 3 & $25 \cdot 0$ & $8 \cdot 3$ & $2: 1$ & 0.750 & 0 & $3: 0$ & 0.250 & 1 \\
\hline 4 & $62 \cdot 5$ & $18 \cdot 8$ & $2: 2$ & 0.375 & 0 & $\begin{array}{l}3: 1 \\
4: 0\end{array}$ & $\begin{array}{l}0.500 \\
0 \cdot 125\end{array}$ & $\begin{array}{l}1 \\
2\end{array}$ \\
\hline 5 & 37.5 & $8 \cdot 7$ & $3: 2$ & 0.625 & 0 & $\begin{array}{l}4: 1 \\
5: 0\end{array}$ & $\begin{array}{l}0.313 \\
0.062\end{array}$ & $\begin{array}{l}1 \\
2\end{array}$ \\
\hline 6 & $68 \cdot 8$ & $15 \cdot 6$ & $3: 3$ & $0 \cdot 312$ & 0 & $\begin{array}{l}4: 2 \\
5: 1 \\
6: 0\end{array}$ & $\begin{array}{l}0.469 \\
0.188 \\
0.031\end{array}$ & $\begin{array}{l}1 \\
2 \\
3\end{array}$ \\
\hline 7 & $45 \cdot 3$ & $8 \cdot 5$ & $4: 3$ & 0.547 & 0 & $\begin{array}{l}5: 2 \\
6: 1 \\
7: 0\end{array}$ & $\begin{array}{l}0.328 \\
0 \cdot 109 \\
0 \cdot 016\end{array}$ & $\begin{array}{l}1 \\
2 \\
3\end{array}$ \\
\hline 8 & $72 \cdot 7$ & $13 \cdot 7$ & $\begin{array}{l}4: 4 \\
5: 3\end{array}$ & $\begin{array}{l}0.273 \\
0.438\end{array}$ & $\begin{array}{l}0 \\
1\end{array}$ & $\begin{array}{l}6: 2 \\
7: 1 \\
8: 0\end{array}$ & $\begin{array}{l}0.219 \\
0.062 \\
0.008\end{array}$ & $\begin{array}{l}2 \\
3 \\
4\end{array}$ \\
\hline 9 & $50 \cdot 8$ & $8 \cdot 1$ & $5: 4$ & 0.492 & 0 & $\begin{array}{l}6: 3 \\
7: 2 \\
8: 1 \\
9: 0\end{array}$ & $\begin{array}{l}0.328 \\
0.141 \\
0.035 \\
0.004\end{array}$ & $\begin{array}{l}1 \\
2 \\
3 \\
4\end{array}$ \\
\hline 10 & $75 \cdot 4$ & $12 \cdot 3$ & $\begin{array}{l}5: 5 \\
6: 4\end{array}$ & $\begin{array}{l}0.246 \\
0.410\end{array}$ & $\begin{array}{l}0 \\
1\end{array}$ & $\begin{array}{r}7: 3 \\
8: 2 \\
9: 1 \\
10: 0\end{array}$ & $\begin{array}{l}0.234 \\
0.088 \\
0.020 \\
0.002\end{array}$ & $\begin{array}{l}2 \\
3 \\
4 \\
5\end{array}$ \\
\hline
\end{tabular}

*No. of activity sites per female represents a single litter for CL and embryo counts, but may include more than one litter for scar counts.

TThe expected percentage of randomly distributed litters that would not be as nearly balanced as is possible for each litter size; for individual sites it is the percentage of sites that would have to be switched from one side to the other at each litter size to change from a random to a maximally balanced distribution.

$\$$ The probability column gives the probability of a female having the specified ratio (including that of its reciprocal) given her number of sites based on the binomial distribution with a probability on each side of 0.5. Number of switches is the minimum number of activity sites that would have to be switched from one side to the other to achieve maximum balance for that number of sites.

litter size. Separate $\chi^{2}$ values were summed resulting in a total $\chi^{2}$ value which was used to test for significant balance at the $95 \%$ confidence level.

Percentage balance was calculated as the number of observed nonrandom activity sites for each species divided by the predicted number of nonrandom sites needed to achieve maximum possible balance between left and right sides. Calculations for embryos of Merriam's kangaroo rat (Dipodomys merriami) provide an example: of 190 pregnant females, 170 had 2 embryos and 20 had 3 embryos for a total of 400 embryos. If the distribution between left and right uterine horns occurred randomly, based on a binomial model with the probability of left and right being equal, we would expect $50 \%$ of the 170 (i.e. 85) females with 2 embryos and $25 \%$ of the 20 (i.e. 5) females with 3 embryos to have all of their embryos implanted in the same uterine horn (see Table 1). To achieve maximum possible balance, each of these 90 females would have to switch 1 embryo to the opposite horn. In the actual sample, all but 1 of the 170 females with a litter size of 2 had 1 embryo in each horn and all of the 20 females with a litter size of 3 had 2 embryos in one horn and 1 in the 


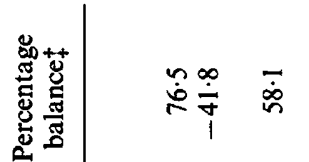

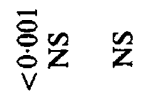

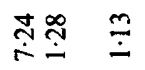

$\stackrel{\infty}{i \infty} \stackrel{\square}{\dot{b}}$
$9 \infty \infty$

$\stackrel{i}{i} \stackrel{m}{\dot{t}}$

오

$\dot{2} \dot{\frac{0}{\pi}}$

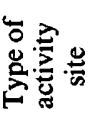

总蒂

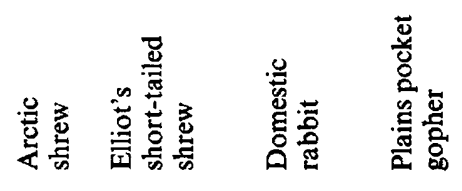

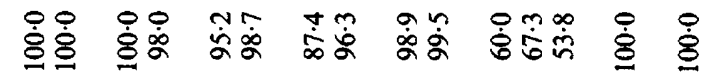

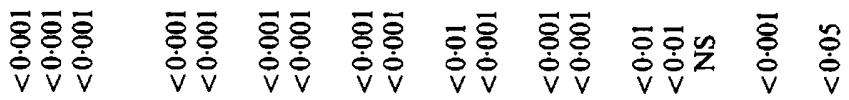

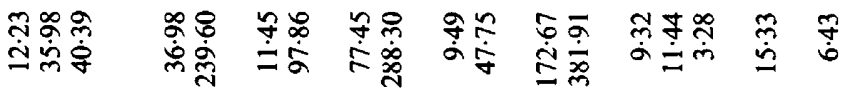

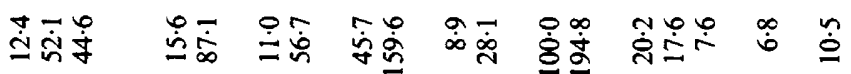

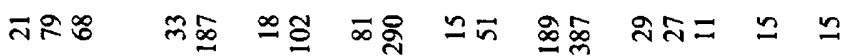

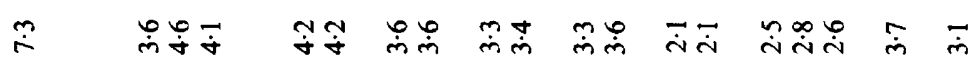

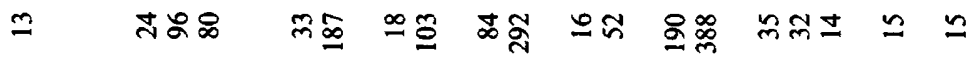

I
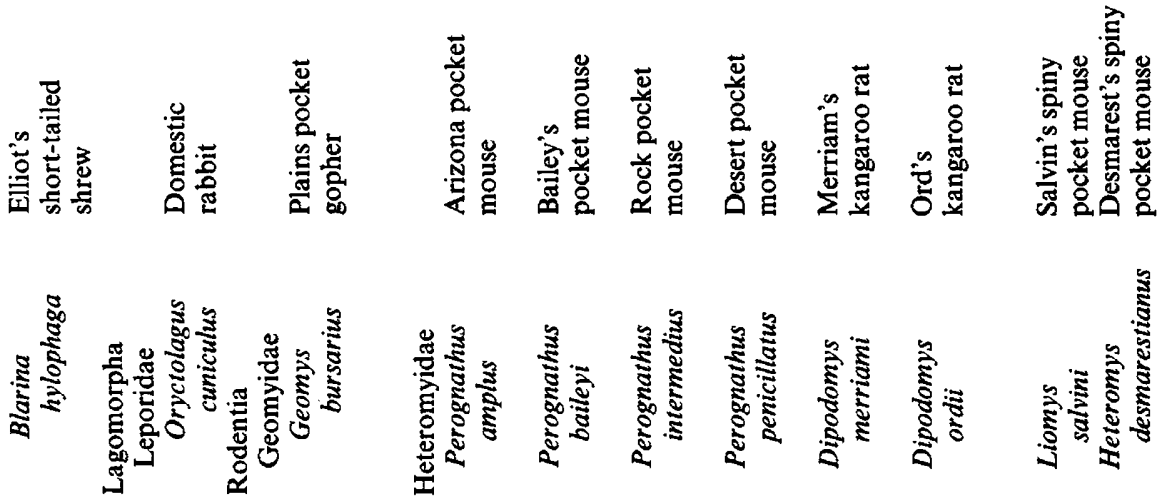


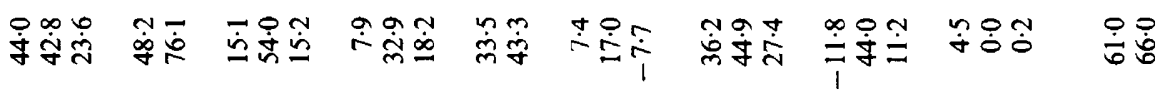

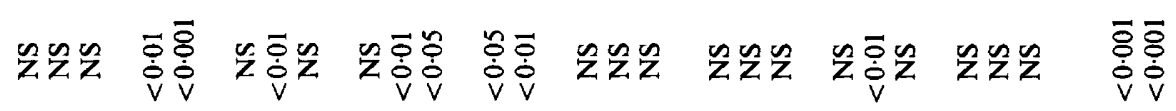

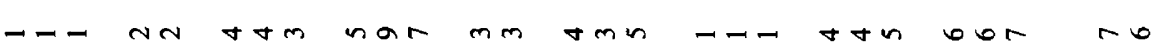

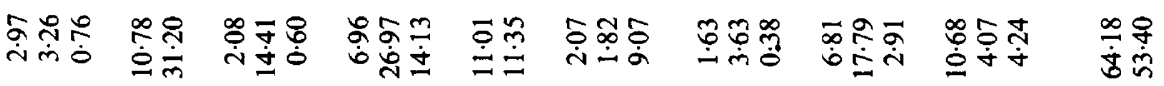

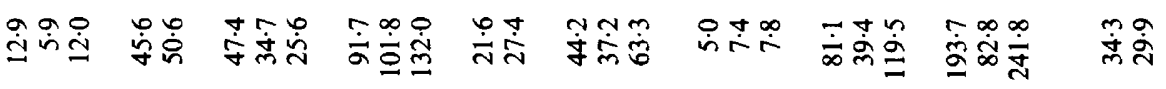

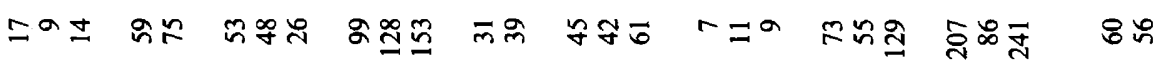

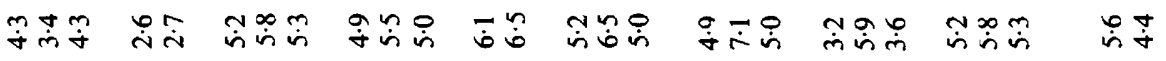

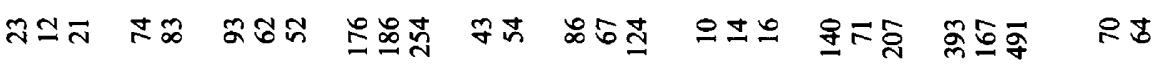

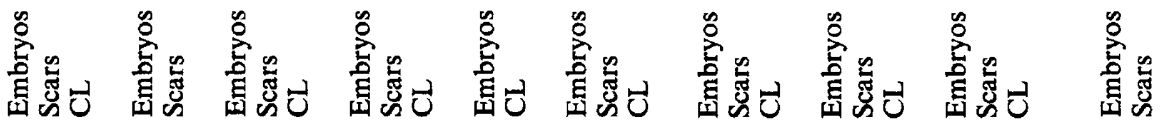

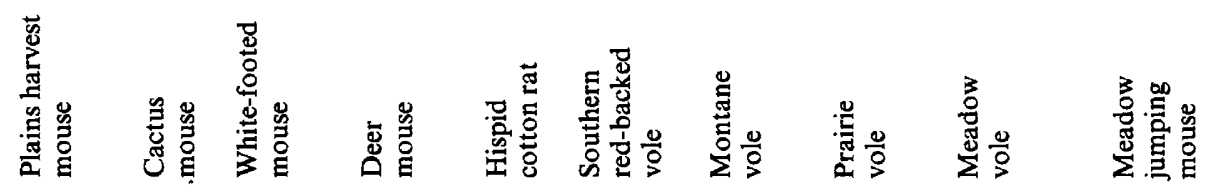

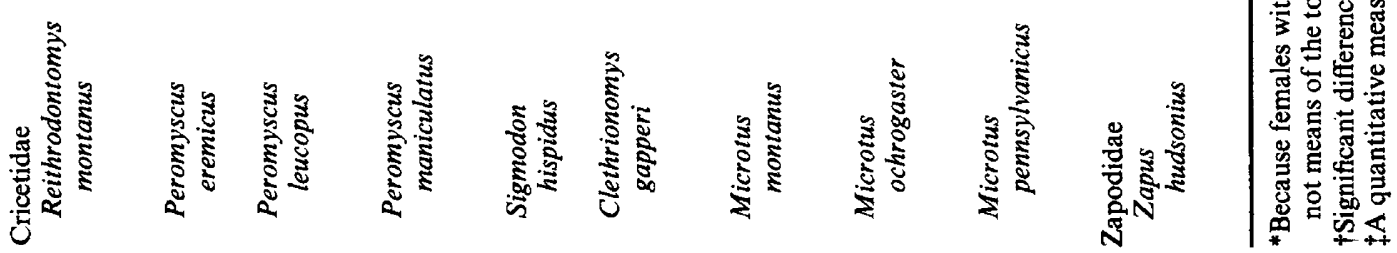


other. Therefore, only a single embryo would need to have been switched to achieve maximum possible balance for this sample. If the expected number of nonrandom embryo placements necessary to achieve maximum balance is the denominator (i.e. 90) and the observed number of nonrandom placements is the numerator (in this case $90-1=89$ ), the result is the observed percentage balance $(89 / 90=99 \%)$. Percentage balance for each type of reproductive activity site for each species was calculated by the same process. Because a distribution of activity sites can be less balanced than random, percentage balance can be negative. For example, if all females of a species had all their activity sites on one side or the other, the percentage balance for that species would be $-100 \%$.

\section{Results}

Distributions of embryos, placental scars and CL in small mammals of 22 species are summarized in Table 2. Thirteen of the species showed significant balance in embryos, ranging from $34 \%$ in the hispid cotton rat (Sigmodon hispidus) to $100 \%$ in several species of heteromyid rodents. Amongst the 8 species not manifesting significant balance of embryos, only the prairie vole (Microtus ochrogaster) showed a negative departure from balance, and this was not significant.

Balanced distributions were observed in one or more species within two of the three orders examined. Within the Insectivora, the arctic shrew (Sorex arcticus) showed significant balance of embryos (76\%), but distribution of CL did not depart from random. For Elliot's short-tailed shrew (Blarina hylophaga) for which we had only scar data on a sample of 12 females, balance was $58 \%$, but the departure from random was not significant. The domestic rabbit (Oryctolagus cuniculus), the single species of lagomorph examined, exhibited no significance balance.

Balance was observed in all families of rodents represented. The plains pocket gopher (Geomys bursarius), the only geomyid examined, exhibited significant balance in embryos, scars and CL, with percentage balance ranging from $57 \%$ for scars to $77 \%$ for embryos. Heteromyid rodents manifested the highest and most consistent balance of any family in our study. With only a single exception, balance was significant for every type of activity site for all of the 8 species examined. Degree of balance was often near $100 \%$. The only nonsignificant sample was of CL data from 14 Ord's kangaroo rats (Dipodomys ordii): the percentage balance in CL (54\%) was only slightly less than for embryos $(60 \%)$, which was significant.

Amongst the cricetid rodents examined, balance was more the exception than the rule. Significant balance was observed for all activity sites examined in cactus mice (Peromyscus eremicus) and hispid cotton rats, but the distribution of embryos was not balanced in any other member of this family. Scars and CL were significantly balanced in deer mice ( $P$. maniculatus) although percentage balance was low (33\% for scars and $18 \%$ for $\mathrm{CL}$ ). Two species, white-footed mice ( $P$. leucopus) and prairie voles (Microtus ochrogaster), had significant balance in scar counts but not for embryos or CL. Higher percentages of balance in scar counts than in embryos or CL were observed in all cricetids except plains harvest mice (Reithrodontomys montanus) and meadow voles ( $M$. pennsylvanicus).

Meadow jumping mice (Zapus hudsonius), the only zapodid examined, manifested significant balance in both embryos and scars.

\section{Discussion}

\section{Balance and uterine morphology}

Balance of embryos can be achieved by several processes. Ovarian mechanisms involve balanced ovulation with subsequent implantation in the corresponding uterine horn. Uterine mechanisms involve random ovulation followed by transuterine migration of unbalanced blastocysts and/or selective resorption of unbalanced embryos. Coelomic migration of blastocysts has 
been observed (Boyd et al., 1944), and could theoretically be a mechanism for achieving balance, but is apparently uncommon (Wimsatt, 1975).

In polytocous species with uterine morphology conducive to transuterine migration of blastocysts, significantly balanced embryo distributions may be the rule rather than the exception. Uterine morphology has been described adequately for only a small percentage of mammalian genera (Mossman, 1977), and even fewer have been analysed for reproductive balance. It is therefore impossible to examine this association thoroughly, but we can provide a preliminary evaluation.

According to Mossman (1977), bicornuate uteri characterize all insectivores, carnivores and hyracoids that have been examined, some bats, some rodents, and some artiodactyls; duplex uteri were found in all lagomorphs examined, some bats, some rodents, and some artiodactyls. Bicornuate uteri are generally more conducive to transuterine migration than are duplex uteri, but some species with bicornuate uteri have a septum between the cornua that inhibits most migration (e.g. sheep and cows: Wimsatt, 1975).

Uterine balance by migration of blastocysts after random ovulation has been described for 3 species of shrews, Sorex araneus (Brambell, 1935), S. minutus (Brambell \& Hall, 1936), and Suncus murinus Dryden, 1969). Sorex palustris probably shows the same pattern, but data on implantation sites were reported for only 6 females (Conaway, 1952). Our data on arctic shrews also conform to this pattern as evinced by significant balance in the distribution of embryos but not in CL. Our only female with embryos and CL exhibited counts consistent with transuterine migration (CL-5 left, 3 right; embryos-4 left, 4 right). Our data for Elliot's short-tailed shrew do not allow us to examine the question of mechanism because we only have scar counts. Although this species showed $58 \%$ balance in scars, the distribution did not differ statistically from random. We suspect that a larger sample with data on embryos and CL would reveal a pattern like that reported for other shrews.

We know of no reports of randomly distributed embryos in any species known to have a uterus conducive to transuterine migration, and several published data are consistent with the hypothesis that species with uterine morphology conducive to transuterine migration will invariably exhibit balanced embryo distributions. For example, rock hyraxes (Procavia capensis) were reported to balance embryo distribution by transuterine migration (Millar, 1971). We also found several reports of transuterine migration in carnivores, but in no case did the investigators analyse for balance. For example, transuterine migration is common in raccoons (Procyon lotor) (Llewellyn \& Enders, 1954) and mongooses (Herpestes auropunctatus) (Pearson \& Baldwin, 1953).

Embryo and corresponding CL data were found in the literature for domestic dogs and pigs and for wild-caught eastern moles (Scalopus aquaticus). All three species exhibit transuterine migration. In a combined sample of 35 dogs (Anderson \& Simpson, 1973; Evans, 1974), balance was $72 \%$ for embryos but only $23 \%$ for CL. Warwick (1926) did not provide data but described a similar pattern for domestic pigs, in which transuterine migration was elegantly demonstrated experimentally by Dziuk, Polge \& Rowson (1964). Data for pigs were presented by Corner (1921), and when analysed (Biggers, Finn \& McLaren, 1962) indicated that an ovum from one ovary was as likely to implant in the opposite uterine horn as the adjacent one. When analysed by our procedure we calculated balance of CL at $-9.4 \%$ for a sample of 22 pregnant sows, and balance of embryos at $59 \%$ for 60 sows showing unbalanced ovarian activity. Similarly, data on pregnant eastern moles (Conaway, 1959) also show no balance in CL distribution but $67 \%$ balance in embryo implantation sites.

In species with a uterus in which transuterine migration of blastocysts is difficult, i.e. a duplex uterus or a bicornuate uterus with a septum or cervical canal separating the cornua, balance in embryos can be achieved only by selective prenatal loss or balanced ovarian activity. The single lagomorph and all the rodents we studied probably have one or these uterine types, but documentation confirming this was found only for Merriam's kangaroo rats, Ord's kangaroo rats, desert pocket mice, and plains pocket gophers (Nielson, 1940). King \& Mossman (1974) noted that the meadow jumping mouse exhibited a bicornuate uterus on gross examination, but no data were 
reported on shape of the cervical canal. No suggestion of transuterine migration was detected in our small sample of pregnant females with $\mathrm{CL}$ and embryo counts, and therefore we tentatively include meadow jumping mice in the category of having uterine morphology that inhibits migration of blastocysts.

None of the species we studied had discernible rates of prenatal loss sufficient to act as a sole mechanism for achieving balance of embryos when ovulation is random. Superovulating species that have small litters (including two species of bats, some elephant-shrews, a South American rodent, and pronghorns; reviewed by Wimsatt, 1975) probably fit this pattern, but examination of the many papers cited by Wimsatt (1975) failed to produce data on the distribution of ovulation sites adequate for our analysis. Implantations after induced ovulation in house mice (Mus musculus) also may become more evenly distributed in the uterus by differential loss of embryos (McLaren, 1963).

The third potential mechanism, balanced ovarian activity, was observed in our data. Thirteen of the 20 species of lagomorph and rodent that we examined exhibited significant balance in the distribution of embryos, but we have CL data to test for ovarian control of balance in only three of these. The plains pocket gopher displayed $77 \%$ balance in embryos and $66 \%$ balance in CL, both highly significant. In hispid cotton rats balance of embryos was $34 \%$ and that in CL $43 \%$, both significant. The Ord's kangaroo rat, with $60 \%$ balance in embryos and $54 \%$ balance in CL, may also follow this pattern, but the distribution of CL for the 14 females is not statistically different from random. We suspect that a larger sample would reveal significant balance in CL as well. However, the $10-20 \%$ estimated intrauterine mortality reported for this species by Hoditschek \& Best (1983) may indicate partial uterine control of balance, if unbalanced embryos have a higher than average probability of being resorbed.

More data clearly are needed to determine whether or not a uterine morphology that inhibits blastocyst migration is invariably associated with balanced ovarian activity in species characterized by a balanced distribution of embryos. The existing reports of random distribution of embryo implantation sites are consistent with this pattern, in that several species with uterine morphology thought to inhibit migration exhibit random distributions of $\mathrm{CL}$ and embryos. House mice (Graham, 1966) and guinea-pigs (Cavia porcellus) (Meczynski, 1974) have a Y-shaped cervical canal, uterine morphology thought to inhibit transuterine migration of blastocysts (Mossman, 1977), and neither species exhibits balance in either ovulation or implantation sites (mouse: Danforth \& de Aberle, 1928; Falconer et al., 1961; McLaren, 1963; guinea-pig: Ibsen, 1928; Eckstein, McKeown \& Record, 1955). The red-backed voles, Clethrionomys glareolus (Brambell \& Rowlands, 1936) and C. gapperi (Table 2), have random distributions of embryos and CL, but we have no information on uterine morphology. Also, the Japanese field vole, Microtus montebelli, like the 3 species of Microtus we examined, exhibited random distribution of embryos (Kaneko, 1978), but again we have no data on uterine morphology. Balance in ovarian activity within litters has not been reported previously. It raises the possibility that physiological mechanisms controlling numbers of ovulations in species exhibiting this characteristic may differ from those in species exhibiting a random distribution of ovulation sites.

\section{Evolutionary considerations}

Bilateral balance of embryos may evolve either because it is directly beneficial to individuals or because it is an indirect effect of other adaptive physiological mechanisms. In species with uterine morphology conducive to transuterine migration, balance of embryos may arise as a side effect of mechanisms for spacing embryos within the uterine horns, and may be ubiquitous in these species.

In species with uterine morphology that inhibits transuterine migration, we suspect that balance of embryos usually will arise only if it is directly beneficial (although theoretically the balanced ovarian activity might be the primary adaptive trait, e.g. balanced ovarian activity hypothetically 
might be a mechanism for tigher control of litter size, and balance of embryos may be an indirect effect).

We suggest two potential benefits for bilateral balance of embryos in polytocous species. First, if embryo crowding and placement affects viability, e.g. as in domestic rabbits (Duncan, 1969; Johnson, Gilbert, Meschia \& Battaglia, 1985), bilateral balance should reduce crowding and increase reproductive success. Secondly, bilateral balance of embryos should result in a more symmetrical distribution of weight gain during pregnancy, providing less interference with normal locomotion. Equal distribution of weight should be more important for species dependent on jumping or rapid cursorial locomotion, and for species with small litters of large, precocial young. Because the uterus is suspended by mesentery, it obviously is capable of appreciable internal compensation. With large litters and/or small altricial young the physical/gravitational advantage of balance probably is minimal.

If balance of embryos is advantageous in a species for any reason, one with small litter size should experience greater selection for balance than one with large litter size because balanced litters will occur by chance alone less frequently if litter size is small (Table 1). For example, with a litter of two in a species lacking a balancing mechanism, $50 \%$ of the litters would be unbalanced and $25 \%$ of the implantation sites would have to be switched from one side to the other to achieve maximum balance. It was counter intuitive, and therefore interesting to us, that the percentage of switches needed to achieve maximum balance is lower for larger litter sizes and is remarkably low for litter sizes such as 9 and $10(8 \cdot 1$ and $12 \cdot 3 \%$, respectively: Table 1$)$. Therefore, if maximum balance is important we would expect the highest selection coefficients for a mechanism to achieve it in species having small litters, especially a litter size of two.

\section{Phylogenetic relationships}

Are the phylogenetic patterns in our data consistent with our evolutionary hypotheses? The most striking phylogenetic pattern in our data is that all species of heteromyid rodents examined exhibited balanced embryo distributions, suggesting that balance is characteristic of the family. Most of the heteromyids we examined are desert inhabitants, although both species of spiny pocket mice are tropical. Ord's kangaroo rat is more of a grassland species than Merriam's kangaroo rat or any of the pocket mice examined. Ord's kangaroo rat also shows a lower percentage balance than the other species. The left-right distribution of embryos in our sample of this species was significantly greater in left than right $(61 \%$ left) so perhaps our sample is atypical, or this species may differ from other heteromyids in the use of the two sides of the reproductive tract. Most notably, the family is characterized by species that depend in large part on quickness to escape predators (two genera exhibit jumping style locomotion), young with high relative weights at birth (Millar, 1977), and small litter sizes (Millar, 1977), three characteristics we suggested as being correlated with increased selection for balanced distribution of embryos.

Balance in plains pocket gophers, family Geomyidae, which together with the Heteromyidae comprises the superfamily Geomyoidea, may be a characteristic retained since last sharing a common ancestor with the heteromyids. We would not have predicted strong selection for balance in association with the fossorial habits of pocket gophers. However, members of the heteromyid genus Perognathus are also partly fossorial, possibly indicating that fossorial living may select for balance through some unidentified advantage.

Meadow jumping mice are more closely related to cricetids than to heteromyids, but like some heteromyids use a jumping style of locomotion when quick movements are required. However, young are small and litter size is large, so we would predict the potential for internal shifts of the uterine horns to equalize weight distribution. Interestingly, jumping mice exhibit somewhat intermediate balance, showing significant balance for both scars and embryos (66 and $61 \%$, respectively), but appreciably less balance than most heteromyids.

Amongst the cricetids, cactus mice, an arid land component of small mammal communities 
often dominated by heteromyids, balance reproductive activity to a greater degree than do the other members of this family we examined, especially its forest and grassland congeners, whitefooted mice and deer mice. Cactus mice are not known to be more saltatory than the two congeners, nor is there reason for thinking that uterine crowding would be a stronger factor in this species than in other species of Peromyscus examined. If further study reveals that cactus mice exhibit balance in ovarian activity, as we predict, ovarian balance may prove to be important for tight regulation of litter size in an arid environment, and uterine balance may be a side effect with no direct adaptive significance.

Hispid cotton rats, the only other cricetid studied that balances embryos, typically have large litters (mean $=6 \cdot 1$ for our sample), at least in the northern parts of its distribution (Mattingly \& McClure, 1982). This species is the largest and most distantly related of the cricetids studied. A grass-eating foliovore ecologically similar to voles, hispid cotton rats are believed to have evolved in warm North American grasslands (Martin, 1979). Since the Pliocene cotton rats have become widespread in grassy habitats from Panama to Nebraska (Hall, 1981). Balance of body weight does not seem to be a likely selective pressure in large-littered temperate zone populations, although it may have been more so in tropical environments in which litter size is lower. Even in large-littered populations the young are relatively precocial at birth, and therefore balance may be a primitive characteristic of this species. Alternatively, it may be recently evolved in northern populations in response to likely embryo crowding in utero due to rapid increase in litter size concomitant with northward dispersal (Kilgore, 1970). Data on geographic variation in uterine capacity and reproductive balance in cotton rats could be used to test between these possibilities.

Overall, the phylogenetic patterns in our data are only partly consistent with our evolutionary hypotheses, but our search for evolutionary explanations has led to several testable research questions.

This study was supported by funds made available to E.C.B. from National Science Foundation Grants GB-7824, GB-13096, GB-31862X, GB-41233X, and BMS73-02027 A02 to the Grassland Biome, U.S. International Biological Program and from the Graduate School, University of Minnesota, D.D.B. was supported in part by NHLBI Grant T32-H107055-09. We thank T. H. Fleming, H. W. Garner, H. H. Genoways, K. M. van de Graaff, R. L. Packard, W. F. Stevens, R. M. Timm and J. O. Whitaker, Jr for unpublished data; R. S. Hoffmann and J. K. Jones, $\mathrm{Jr}$ for initiating the studies at the northern IBP sites; many students and field assistants for help with trapping and data compilation; $\mathrm{H}$. W. Mossman for direction to the literature on comparative uterine morphology; C. R. Weinberg for statistical consultation; H. W. Mossman and O. P. Pearson for critical review of the manuscript; and S. Watkins for help in preparation of the manuscript.

\section{References}

Anderson, A.C. \& Simpson, M.E. (1973) The Ovary and Reproductive Cycle of the Dog (beagle). Geron-X, Inc., Los Altos.

Asdell, S.A. (1964) Patterns of Mammalian Reproduction, 2nd edn. Cornell University Press, Ithaca.

Asdell, S.A. (1966) Evolutionary trends in physiology of reproduction. Symp. zool. Soc. Lond. 15, 1-13.

Baird, D.D. \& Birney, E.C. (1982) Characteristics of dispersing meadow voles Microtus pennsylvanicus. Am. Midland Nat. 107, 262-283.

Baird, D.D., Timm, R.M. \& Nordquist, G.E. (1983) Reproduction in the arctic shrew, Sorex arcticus. $J$. Mammal. 64, 298-301.

Biggers, J.D., Finn, C.A. \& McLaren, A. (1962) Longterm reproductive performance of female mice. II.
Variation of litter size with parity. J. Reprod. Fert. 3, 313-330.

Boyd, J.D., Hamilton, W.J. \& Hammond, J., Jr (1944) Transuterine ('internal') migration of the ovum in sheep and other mammals. J. Anat. 78, 5-14.

Brambell, F.W.R. (1935) Reproduction in the common shrew (Sorex araneus Linnaeus) I. The oestrus cycle of the female. Phil. Trans. R. Soc. Lond. 225B, 1-62.

Brambell, F.W.R. \& Hall, K. (1936) Reproduction of the lesser shrew (Sorex minutus Linnaeus). Proc. zool. Soc. Lond. 1936, 957-969.

Brambell, F.W.R. \& Rowlands, I.W. (1936) Reproduction of the bank vole (Evotomys glareolus Schreber). I. The oestrus cycle of the female. Phil. Trans. R. Soc. Lond. 226B, 71-120. 
Conaway, C.H. (1952) Life history of the water shrew (Sorex palustris navigator). Am. Midland Nat. 48, 219-248.

Conaway, C.H. (1959) The reproductive cycle of the eastern mole. J. Mammal. 40, 180-194.

Corner, G.W. (1921) Internal migration of the ovum. Bull. Johns Hopkins Hosp. 32, 78-83.

Danforth, C.H. \& de Aberle, S.B. (1928) The functional interrelation of the ovaries as indicated by the distribution of foetuses in mouse uteri. Am. J. Anat. 41, $65-74$.

Dryden, G.L. (1969) Reproduction in Suncus murinus. $J$. Reprod. Fert., Suppl. 6, 377-396.

Duncan, S.L.B. (1969) The partition of uterine blood flow in the pregnant rabbit. J. Physiol., Lond. 204, 421-433.

Dzuik, P.J., Polge, C. \& Rowson, L.E.A. (1964) Intrauterine migration and mixing of embryos in swine following egg transfer. J. Anim. Sci. 23, 37-42.

Eckstein, P., McKeown, T. \& Record, R.G. (1955) Variation in placental weight according to litter size in the guinea-pig. $J$. Endocr. 12, 108-114.

Evans, H.E. (1974) Prenatal development of the dog. In The Newer Knowledge About Dogs, pp. 18-28. Gaines Dog Research Center, White Plains.

Falconer, D.S., Edwards, R.G., Fowler, R.E. \& Roberts, R.C. (1961) Analysis of differences in the numbers of eggs shed by the two ovaries of mice during natural oestrus or after superovulation. J. Reprod. Fert. 2, 418-437.

French, N.R., Grant, W.E., Grodzinski, W. \& Swift, D.M. (1976) Small mammal energetics in grassland ecosystems. Ecol. Monogr. 46, 201-220.

Graham, C.E. (1966) Cyclic changes in the squamocolumnar junction of the mouse cervix uteri. Anat. Rec. 155, 251-260.

Hall, E.R. (1981) The Mammals of North America, 2nd edn. John Wiley and Sons, New York.

Hoditschek, B. \& Best, T.L. (1983) Reproductive biology of Ord's kangaroo rat (Dipodomys ordii) in Oklahoma. J. Mammal. 64, 121-127.

Ibsen, H.L. (1928) Prenatal growth in guinea-pigs with special reference to environmental factors affecting weight at birth. J. exp. Zool. 51, 51-94.

Johnson, R.L., Gilbert, M., Meschia, G. \& Battaglia, F.C. (1985) Cardiac output distribution and utero placental blood flow in the pregnant rabbit: a comparative study. Am. J. Obstet. Gynecol. 151, 682-686.

Kalin, O.T. (1976) Distribution, relative abundance, and species richness of small mammals in Minnesota, with an analysis of some structural characteristics of habitats as factors influencing species richness. Ph.D. thesis, University of Minnesota.

Kaneko, Y. (1978) Variations of the number of embryos in Microtus monte belli (Milne-Edwards). $J$. Mammal. Soc. Japan 7, 121-129.

Kilgore, D.L., Jr (1970) The effects of northward dispersal on growth rate of young, size of young at birth, and litter size in Sigmodon hispidus. Am. Midland Nat. 84, 510-520.

King, B.F. \& Mossman, H.W. (1974) The fetal membranes and unusual giant cell placenta of the jerboa (Jaculus) and jumping mouse (Zapus). Am. J. Anat. 140, 405-431.

Kitchener, D.J. (1975) Reproduction in female Gould's wattled bat, Chalinolobus gouldii (Gray) (Vespertilionidae), in western Australia. Aust. J. Zool. 23, 29-42.

Lampe, R.P., Jones, J.K., Jr, Hoffmann, R.S. \& Birney, E.C. (1974) The mammals of Carter County, southeastern Montana. Occas. Papers Mus. Nat. Hist., Univ. Kansas 25, 1-39.

Llewellyn, L.M. \& Enders, R.K. (1954) Trans-uterine migration in the raccoon. $J$. Mammal. 35, 439.

Martin, R.A. (1979) Fossil history of the rodent genus Sigmodon. Evol. Monogr. 2, 1-36.

Mattingly, D.K. \& McClure, P.A. (1982) Energetics of reproduction in large-littered cotton rats (Sigmodon hispidus). Ecology 63, 183-195.

McLaren, A. (1963) The distribution of eggs and embryos between sides in the mouse. J. Endocr. 27, 157-181.

Meczynski, S. (1974) Morphohistological structure of female genital organs in sousliks. Acta theriol. 19, 91-106.

Millar, J.S. (1977) Adaptive features of mammalian reproduction. Evolution 31, 370-386.

Millar, J.S. (1981) Pre-partum reproductive characteristics of eutherian mammals. Evolution 35, 1149-1 163.

Millar, R.P. (1971) Reproduction in the rock hyrax (Procavia capensis). Zool. Africana 6, 243-261.

Mossman, H.W. (1977) Comparative anatomy. In Biology of the Uterus, pp. 19-34. Ed. R. M. Wynn. Plenum Press, New York.

Nielson, P.E. (1940) The fetal membranes of the kangaroo rat, Dipodomys, with a consideration of the phylogeny of the Geomyoidea. Anat. Rec. 77, $103-127$.

Ohsumi, S. (1964) Comparison of maturity and accumulation rate of corpora albicantia between the left and right ovaries in Cetacea. Sci. Rep. Whales Res. Inst. Tokyo 18, 123-149.

Pearson, O.P. (1949) Reproduction of a South American rodent, the mountain viscacha. Am. J. Anat. 84, 143-174.

Pearson, O.P. \& Baldwin, P.H. (1953) Reproduction and age structure of a mongoose population in Hawaii. $J$. Mammal. 34, 436-447.

Reichman, O.J. \& van de Graaf, K.M. (1975) Association between ingestion of green vegetation and desert rodent reproduction. J. Mammal. 56, 503-506.

Rowlands, I.W. \& Weir, B.J. (1984) Mammals: Nonprimate eutherians. In Marshall's Physiology of Reproduction, 4th edn. Vol. 1: Reproductive Cycles of Vertebrates, pp. 455-658. Ed. G. E. Lamming. Churchill-Livingstone, Edinburgh.

Slijper, E.J. (1949) On some phenomena concerning pregnancy and parturition of the Cetacea. Bijdr. Dierk. 28, 416-448.

Stearns, S.C. (1976) Life-history tactics: a review of the ideas. Q. Rev. Biol. 51, 3-47.

Stearns, S.C. (1977) The evolution of life history traits. Ann. Rev. Ecol. Syst. 8, 145-171.

Timm, R.M. (1975) Distribution, natural history, and parasites of mammals of Cook County, Minnesota. Occas. Papers Bell Mus. Nat. Hist. 14, 1-56.

Warwick, B.L. (1926) Intra-uterine migration of ova in the sow. Anat. Rec. 33, 29-33.

Weir, B.J. (1971) Some notes on reproduction in the Patagonian mountain viscacha, Lagidium boxi (Mammalia: Rodentia). J. Zool., Lond. 164, 463-467. 
Weir, B.J. \& Rowlands, I.W. (1973) Reproductive strategies of mammals. Ann. Rev. Ecol. Syst. 4, 139-163.

Wimsatt, W.A. (1945) Notes on breeding behavior, pregnancy, and parturition in some vespertilionid bats of the eastern United States. J. Mammal. 26, 23-33.

Wimsatt, W.A. (1975) Some comparative aspects of implantation. Biol. Reprod. 12, 1-40.
Wimsatt, W.A. (1979) Reproductive asymmetry and unilateral pregnancy in Chiroptera. J. Reprod. Fert. 56, 345-357.

Received 10 December 1984 